\title{
CONTRIBUIÇÃO AO CONHECIMENTO DO TRIATOMA MACULATA (ERICHSON, 1848) E DO TRIATOMA PSEUDOMACULATA CORREIA E ESPÍNOLA, 1964

\author{
(HEMIPTERA, REDUVIIDAE) *
}

Archibaldo Bello Galvão **

\begin{abstract}
O reconhecimento das espécies Triatoma maculata (Erichson, 1848) e Triatoma pseudomaculata (Correia e Espinola, 1964), tem sido e continua sendo objeto de muita controvérsia. Essas espécies foram também confundidas pelo autor durante algum tempo.

Possivelmente, a razão dessa confusão está na precária descrição de certas estruturas dessas espécies, de modo que nāo se pode ter certeza de sua distribuição no Brasil.

Um estudo comparativo cuidadoso envolvendo ambas as espécies está aqui relatado e concluiu-se que é o T. pseudomaculata $e$ não o T. maculata que está sendo encontrado nos Estados do Piauí, Ceará, Rio Grande do Norte, Paraíba, Pernambuco, Alagoas, Bahia, Minas Gerais, Goiás e Distrito Federal - Brasilia.
\end{abstract}

O autor, levando em consideração o fato de ter confundido espécies tão distintas, como Triatoma maculata Erichson, 1848 e o Triatoma pseudomaculata Correia e Espinola, 1964 e de que ainda sejam as mesmas confundidas por pesquisadores do Nordeste, apresenta este trabalho que consta dos seguintes tópicos referentes a essas espécies:

1) O nome "maculata" nos autores;

2) Redescrição do T. maculata (Erichson, 1848);

3) Seus caracteres somáticos e cromáticos diferenciais;

4) Estereofotos totais do macho e da fêmea;

5) Microfotografias dos rostros e estruturas componentes das genitálias externas do macho e da fêmea;
6) Mapa de sua distribuição regional e política.

\section{1) O NOME "MACULATA" NOS AUTORES}

Até a data em que fol publicado o trabalho de Correia e Espinola (5), descrevendo o Triatoma pseudomaculata, após estudos comparativos de morfologia externa e de compatibilidade reprodutiva, esta espécie era confundida com o Triatoma maculata (Erichson, 1848), tendo sido a descrição desta última espécie baseada em material procedente do Suriname (Guiana Holandesa), conforme declara Stoll (14), que a descreve pela primeira vez.

Os estudos de Correia e Espinola, segundo estes autores, foram realizados com espécimes provenientes de Sobral (Ceará)

* Trabalho do Laboratório de Blologia e Controle de Insetos (dirigido pela Dr Alina P. Szumlewicz) do Núcleo Central de Pesquisas em Jacarepaguá, INERu, FroCRUz. Fetto com a ajuda financeira do Conselho Nacional de Pesquisas.

* Pesquisador em Zoologia da SUCAM.

Recebido par publicaçáo em 20.8.73. 
e de Boa Vista e Iranduíque (Território de Roraima).

Em 1967, encontrando Barretto (4) a espécie de Correia e Espínola, em Goiás, opinou sobre a mesma da seguinte maneira:

"Não queremos entrar em maiores discussões sobre o status do triatomineo $\mathrm{em}$ tela, mas, a julgar pelos resultados dos cruzamentos obtidos por Correia e Espínola (12), é possível que o pseudomaculata seja uma subespécie do T. maculata. Seja como for, é esta a primeira vez que se encontra o triatomineo em biótopos naturais no Brasil. Acontece, então, com o pseudomaculata fato semelhante ao que foi observado por Torrealba e Diáz Vásquez na Venezuela, com o maculata".

Em 1969, A. B. Galvão e A. L. M. Carvalho (7), não tendo visto ainda a forma do Suriname que Correia e Espínola estudaram, foram ainda mais radicais que Barretto, quando consideraram espécimes de pseudomaculata encontrados em Goiás, como sinônimo do maculata de Erichson. Verificaram, nesta oportunidade, que os desenhos dos parâmeros e processo mediano do pigóforo, dados por Correia e Espínola para o pseudomaculata, não concordavam inteiramente com essas estruturas encontradas nos espécimes de Goiás, as quais se aproximavam mais dos desenhos dos referidos autores dados para o maculata (Erichson, 1848). Por outro lado, cumpre lembrar que, muito depois da descrição do pseudomaculata, Barretto (3) não tinha ainda conhecimento do trabalho de Correia e Espínola, pois não consta da bibliografia do referido trabalho desse autor.

Mas, se o reconhecimento do pseudomaculata como forma independente do $\mathrm{ma-}$ culata já é admitida no sul do país, o mesmo não se verifica no Nordeste, onde pesquisadores como Lucena (9), Sherlock e Guitton (12), Dobbin e Cruz (6) e Alencar (1), continuam a denominar a forma ali ocorrente como maculata (Erichson, 1843).

Recentemente, porém, Sherlock e 'Serafim (13) já se referem ao pseudomaculata, o que fazem, entretanto, nos seguintes termos:

"Neste Estado temos exemplares dessa espécie $\mathrm{ccm}$ aspectos morfológicos variáveis.

Os nossos estudos ainda não consluíram tratar-se realmente de uma ou de mais es- pécies ou de quais espécies essas variedades seriam.

Não mais foi possivel determinarmos qual o tipo de "maculata" que ocorria em determinada localidade, pois, anteriormente, as variações morfológicas não eram por nós levadas em consideração. Por isso, esses tipos variáveis de hemiptero serão todos designados neste trabalho como Triatoma maculata (Erichson, 1848)".

Embora fazendo alusão ao pseudomaculata e às variedades observadas, Sherlock e Serafim ainda não admitem esta espécie como componente da fauna triatominica do Estado da Bahia, pois consideram o maculata (Erichson, 1848) como a espécie vigente naquela área.

Almeida (2) em trabalho sem data, mas recente - como se pode verificar pelas citaçōes, referindo-se ao maculata (Erichson, 1848) diz o seguinte: "As incriminaçōes a esta última espécie no Brasil, são na verdade, concorrentes a T. pseudomaculata Correia e Espínola, 1964, barbeiro do Nordeste, outrora identificado como $T$. maculata, que em nosso país só foi encontrado no Território de Roraima (Correia e Espinola, 1964)".

Na verdade, o pseudomaculata não ocorre somente na Região Nordeste, como diz Almeida, mas é encontrado também na Região Suleste (Minas Geraiș) e Gentro-Oeste (Goiás). Ademais, continua șendo identificado como T. maculata, eonforme demonstra o que transcrevemos acima. $\mathrm{Pa}$ rece, entretanto, que a mais ampla e densa distribuição do pseudomaculata se dá na Regiāo Nordeste.

A descrição đo atual macutata (Erichscn, 1848) foi feita por Stoll no seu trabalho bilíngue já citado. Ao contrário do excelente desenho que apresenta de "La punaise mouche bigarrée", como denominou a forma em questão, a descrição do naturalista holandês parece, à primeira vista, bastante problemática, de vez que, entre outros caracteres, dá o scguinte: "La trompa est courte, arquée..." 0 vocábulo "arquée" tanto poderia significar "arqueado" como "dobrado", acep̧̧ões completaments diferentes, em se tratando de um problema taxinômico dentro do ordem Hemiptera.

Acontece que o desenho de "La punaise mouche bigarrée" não mostra o rostro, como em desenhos de outros espécimes di- 
ferentes, onde essa estrutura é nitidamente curva; mas, na descrição desses espécimes, emprega Stoll o vocábulo "recourbée", e que não deixa dúvida quanto à significaçāo do vocábulo "arquée" com qua qualifica o rostro do atual maculata (Erichson, 1848), ainda que não tivesse dado à "forma do rostro" o valor taxinôm 'co que só 45 anos mais tarde lhe daria Laporte (8).

Quanto à autoria da espécie, deveu-a Erichson não só ao fato de tê-la denominado segundo as regras nomenclaturais vigentes, como também por havê-la incluído no gênero Conorhinus Laporte, pelo qual Laporte substituiu seu gênero Triatoma hoje prevalecente, o qual foi baseado em outros caracteres válidos como "Rostrum rectum", mas invalidado pelo próprio autor por conter, devido a um equívoco de observação, o caráter "Antennae articulis 3".

t verdade, que, no gênero Conorhinus, Walker (17) colocou sua espécie arenarius, de Santarém (Pará), que nos parece um piratíneo - portanto, de rostro curvo - e que Walker descreveu assim: "Prothorax... fore lobe much longer than the hind lobe... fore femur incrassate". Neiva, entretanto, não a encontrou no British Museum; cancordando com Distant, acha que se deve considerá-la inexistente.

Não é difícil concluir a diversidade de critérios que imperava entre os mais antigos taxinomistas, condição determinada pelas diferentes disponibilidades e capacidade de observação do material entomológico; dificuldade ou ausência de intercâmbio entre os pesquisadores, e, como decorrência desses fatores, pela falta de unanimidade entre os mesmos, no arranjo sistemático dos diversos grupos como, em menor grau, ainda ccorre hoje.

Como quer que fosse, no que tange ao T. maculata (Erichson, 1848), o "nome" como a "forma" criaram raízes, mormente após o trabalho de Correia e Espinola, descrevendo o pseudomaculata e censtatando a presença da espécie de Erichson em limitada área do Brasil.

Parece ter sido Neiva (10) o primeiro a admitir o T. maculata (Erichson, 1818) $\mathrm{em}$ nosso país.

Vale a pena transcrever o cus diz Arthur Neiva, pioneiro nos estudos hemipterológicos no Brasil:

"Pátria: Guiana Ing!esa, Brasil, Venezuela.
Estudamos o tipo que se acha no Museu de Berlim, ainda em bom estado de conservação. É uma espécie que apresenta algumas variações, não só no colorido geral, como também nas manchas do conexivo, as quais são ora de largura uniforme ora apresentando as manchas ocráceas mais largas; outros exemplares apresentam as manchas negras estreitando-se ao atingir os bordos do conexivo.

Encontramos esta espécie não raramente freqüentando as habitações de 3 Estados do Brasil Central".

Como se vê, Neiva, estudando não só o "tipo" como "outros exemplares", observou "variações não só no colorido geral, como também nas manchas do conexivo, as quais são "de largura uniforme..." Realmente, o maculata é mais claro, enquanto o pseudomaculata é mais escuro e, nesta espécie, as manchas negras conexivais são de largura uniforme. Por outro lado, "as manchas ocráceas mais largas" e "as manchas negras estreitando-se ao atingir os bordos do conexivo" são caracteres que se enquadram na definição do maculata de Erichson.

Quanto à distribuição geográfica, Neiva indica a Guiana Inglesa, o que se não tem confirmação, parece até mesmo mais provável do que o Suriname, pois que se acha mais próxima da área em que se tem com freqüência encontrado esta єspécie, isto è, Venezuela, Roraima (Brasil) e Colômbia: Esta última indicação foi confirmada por informação epistolar do Dr. Lauro Travassos Filho, do Instituto Butantan (16).

A especificação " 3 Estados do Brasil Central" e a mistura de caractores cromáticcs das espécies em causa, revelam a origem da indeterminação cue se prolongoụ, por tantos anos, de ouas formas bam distintas. Indeterminação oue perdurou e ainda p:rdura, nas listas de distribuiçăo geográfica de não poucos pesquisadores.

De tudo o cue dissemos sobre esta espécie, forçoso é transcrevermos as palavras de Correia e Espinola no trabalho em que descrevaram o pseudomaculata, separando-o do verdadeiro maculata: "Erichson considera a espécio como scndo de Stoll, mas logo abaixo a descreve como nova, com o nome de lutulenius. De cualquer maneira, julgamos cue o Conorhinus maculatus deva provalec $₫$ com o nome atual de Triatoma maculata." 
Infelizmente, não nos foi possivel consultar o volume III do trabalho de Schomburgh, de onde Correia e Espínola transcrevem os dizeres de Erichson. Tinhamos conhecimento de "lutulentus" através dos trabalhos de Walker e de Neiva e Lent (11), como sinôn:mo do Panstrongylus geniculatus (Latreille, 1811) e não de maculata como consideram os autores citados.

Quanto a nós, compreende-se que o engano em que incorremos, confundindo formas tāo distintas, e a ainda existente alienação de trabalho tão importante, não só sob o ponto de vista taxinômico, como conseqüentemente epidemiológico, são fatos que nos levam a apresentar este trabalho.

Não queremos, porém, encerrar as consideraçōes preliminares acima, sem transcrever o que dizem Torrealba e Vásquez (15) a respeito da espécie em causa, no trabalho citado por Barretto:

"En esta breve publicación, nos vamos a referir a la localización de focos e criaderos extra-domesticos de Eutriatoma maculata (Erichson, 1848) Pinto, 1931. Triatomideo que no tiene en Venezuela la importancia del Rhodnius prolixus (Stal, 1859), pero que, a pesar de esto, es uno de los vectores del mal en el pais, por su abundancia en las vivendas rurales de muchos Estados, y por haberse encontrado en infección natural por $S$. cruzi, y que en algunas regiones es considerado como el principal vector, como ocurre en las costas del Estado Falcón."

\section{2) DESCRIÇAO DO "MACULATA" (ERICHSON, 1848)}

Colorido geral pardo escuro, com áreas claras extensas. Cabeça mais clara no dorso com $1+1$ áreas claras falciformes, desde as gulas até os cômoros ocelares e $1+1$ áreas claras pequenas, arredondadas, próximas aos mencionados cômoros e para fora das bases das áreas falciformes; genas ultrapassando o clípeo; julgas mais ou menos desenvolvidas e recobertas, como a porção central da cabeça entre os olhos, por uma área mais estreita; 10 segmento antenal revestido de pelos dourados diminutos e não atingindo o ápice da cabeça; 2 segmento, revestido de pelos claros pouco mais nítidos que os do $1{ }^{\circ}$, cerca de 6 vezes maior que o 10 e aproximadamente do mesmo diâmetro; $3 \circ$ e 4 \% segmentos, faltando nos espécimes estudados. Olhos grandes, localizados mais para a face ventral, espaço interocular dorsal cerca de 3 vezes maior que o espaço interocelar; cabeça, vista pelo dorso, ultrapassando, nos limites externos dos olhos, o espaço entre o ápice dos ângulos ântero-externos do colarinho; espaço interocular ventral tão largo quanto a largura do $2^{\circ}$ segmento do rostro; rastro de colorido castanho escuro uniforme; 10 segmento atingindo $o$ ápice dos tubérculos anteníferos; $2{ }^{\circ}$ segmento ultrapassando levemente a margem posterior dos olhos; 39 segmento atingindo a metade do sulco prosternal e revestido de pelos abundantes e longos; pescoço com $1+1$ áreas claras laterais; tórax: ângulos ântero-externos de colarinho como duas garras de base dilatada e ápice mais afilado e recurvando-se para dentro, quase totalmente claros, exceto na porção interna basal que é escura como o restante do colarinho. Pronoto de margens e lobos bem recortados, o lobo posterior emarginado; lobo anterior dividido em duas bossas separadas pelo sulco mediano longitudinal; $1+1$ tubérculos discais claros, a área clara divergindo para a frente, $1+1$ tubérculos marginais claros. Lobo posterior com $1+1$ carenas submedianas nitidas. Tegumento entre as carenas enrugado transversalmente, mas fora delas o enrugamento se apresenta em várias direções; $1+1$ manchas claras arredondadas, fora das carenas e logo atrás do lobo anterior; na margem posterior do lobo posterior, $2+2$ áreas claras mais ou menos circulares: $1+1$ entre as carenas submedianas e $1+1$ nos ângulos posteriores do lobo posterior. Propleuras com nítida mancha clara na porção posterior do escudo, outra mancha clara na porção posterior da mesopleura. Esterno com nitido sulco prosternal no escudo; no mesosterno, um pequeno tubérculo em barra transversal. Depressão escutelar cordiforme, de tegumento enrugado, principalmente na porção posterior; bordos da base do escutelo levemente ondulados sem apresentarem tubérculos; processo escutelar alongado com leves enrugamentos transversais, mas paralelo à face dorsal do abdome. Hemi-élitros predominantemente claros com nervuras salientes e áreas mais ou menos definidas na margem do cório, não atingindo o pigidio nas fêmeas; nos machos, quase alcançando a extremidade livre do abdome. Pernas, pardo-escuras, os tarsos, de tona- 
lidade mais clara com duas garras não apendiculadas; pernas anteriores, implantadas em acetábulos mais aproximados que nas outras pernas; fêmures anteriores e médios apresentando $1+1$ espinhos nitidos sub-apicals na face interna; fêmures posteriores, com ligeira elevação na região dos espinhos sub-apicais, sem apresentá-los entretanto.

Abdome dorsal com o conexivo normalmente expandido. A área escura intersegmentar menor que a área clara e afilando-se para a margem externa. Abdome ventral quase totalmente escuro, exceto as áreas claras do conexivo que sāo semicirculares, como as dorsais.

Material em que foi baseada a redescrição: 1 macho e 3 fêmeas.

Procedência do material estudado: V. Pereira, Surumu, Município de Boa Vista, Território de Roraima, Brasil.

Topótipo: Suriname (Guiana Holandesa).
Distribuição Geográfica: s u r in a me , Guiana Inglesa (?), Brasil, (Roraima), Venezuela, Colômbia.

\section{TRIATOMA PSEUDOMACULATA COR- REIA E ESPINOLA, 1964}

Topótipo - Sobral, Ceará.

Distribuição geográfica - Região Nordeste (Piaui, Ceará, Rio Grande do Norte, Paraíba, Pernambuco, Alagoas e Bahia), Regiāo Suleste (Minas Gerais), Regiāo Centro-Oeste (Goiás) e Distrito Federal) (Fig. 7).

Os exemplares desta espécie que serviram para o estudo comparativo com o $T$. maculata (Erichson, 1848) foram retirados da colônia do Laboratório de Biologia e Controle de Insetos, em Jacarepaguá, onde a espécie é mantida, há cerca de 3 anos, e cujo estoque original fol capturado no Estado de Pernambuco.

\section{3 - CARACTERES SOMÁTICOS E CROMATICOS DIFERENCIAIS}

Localizaçāo

T. maculata
T. pseudomaculata
Colorido geral

(Fig. 1) pardo e s c u ro com áreas pardo escuro com áreas claclaras mais extensas e em ras reduzidas e em menor maior número
Face dorsal da cabeça (Fig. 1) m a i s comprido; segmento basal e médio maiores; 0 distal com pelos mais numerosos e mais longos menor, segmento basal e médio menores; o distal com pelos mais curtos e em menor número
Ângulos ântero-externo do colarinho (Fig. 1) desenvolvidos, c o mo duas garras predominantemente claras de ápice afilado e atingindo o limite posterior dos ocelos. menos desenvolvidos, cilíndricos, mais escuros, o ápice rombo, em ângulo abarto.
Pronoto (Fig. 1) com $4+4$ áreas claras mais extensas; $2+2$ áreas claras menores.
$3+3$ áreas claras mais extensas; $1+1$ áreas claras menores. 
Escutelo (Fig. 1)

Conexivo (Fig. 1)

áreas claras, relativamente extensas; áreas escuras estreitando-se para o bordo externo.

Machol - mais volumosa; parâmeros, dobrando-se para $o$ ápice, este com cabeça desenvolvida, não apresentando entalhe no perfil;

processo mediano do pigóforo, mais curto, de ápice rombo, a base reduzida;

Genitália externa

(Fig, 3, 4, 5, 6) base; adelgaçando-se para 0 ápice. propleura e outra na mesopleura. "phallus" - bem maior, com o processo do endosoma me- processo aproximadamente do mesmo comprimento da base, esta com $1+1$ tubérculos nos bordos póstero-laterais.

com 1 única área clara na propleura.

predominantemente claros. predominantemente escuros. lânico, com pregas laterais mais ou menos paralelas e sem dentes.

Fêmea - $9^{\circ}$ e $10^{\circ}$ tergitos predominantemente escuros; 9 o tergito com $1+1$ áreas claras laterais, 10 o tergito com área clara limitada an ápice; gonocoxitos do 9o segmento de ápice mais largo com pelos mais curtos; gonapófises do $9^{\circ}$.. segmento mais largas em todo o comprimento, o espinho apical mais curto e de ápice rombo; gonapófises, do $8^{\circ} \mathrm{seg}-$ mento de largura uniforme, exceto o ápice onde há um nítido prolongamento interno; gonocoxitos do 8 o segmento, de tonalidade mais clara, retangulares, o eixo transverso maior que o longitudinal.

áreas claras, menos extensas, áreas escuras, de largura uniforme.

Macho - bem mais reduzida; parâmeros, nitidamente arqueado, a cabeça pouco diferenciada e com nítido entalhe anterior visto de perfil;

processo mediano do pigóforo mais comprido de ápice mais afilado, a base mais alta e mais ampla;

"phallus" - bem menor com o processo de endosoma claro, com dentes nitidos, as pregas irregularmente dispostas.

Fêmea $-9^{\circ}$ e $10^{\circ}$ tergitos com áreas claras centrais extensas; 99 tergito com área clara, retangular que se liga à área do $10^{\circ}$ tergito e estendendo-se à quase todo o segmento; gonocoxitos do 9 segmento mais estreitos, afilando-se para o ápice, os pelos do ápice mais longos; gonapófises do $\mathbf{9}^{9}$ segmento afilando-se para o ápice, o espinho apical mais longo e de áp:ce mais agudo; gonapófises do 80 segmento estreitando-se para o ápice que é rombo;

gonocoxitos do 8 o segmento, de tonalidade mais escura, o eixo transverso de comprimento aproximadamente igual ao longitudinal. 


\section{MEDIDAS}

\begin{tabular}{|c|c|c|}
\hline & T. maculata & $\begin{array}{l}\text { T. pseudo- } \\
\text { maculata }\end{array}$ \\
\hline Comprimento total: & $21,5 \mathrm{~mm}$ & $20 \mathrm{~mm}$ \\
\hline Cabeça: ......... & $4 \mathrm{~mm}$ & $2,75 \mathrm{~mm}$ \\
\hline $\begin{array}{l}\text { largura máxima: } \ldots \ldots \ldots \ldots \ldots \\
\text { (inclusive os olhos) }\end{array}$ & $2 \mathrm{~mm}$ & $1,75 \mathrm{~mm}$ \\
\hline largura entre os olhos: $\ldots . .$. & $1,5 \mathrm{~mm}$ & $1 \mathrm{~mm}$ \\
\hline comprimento do rostro: $\ldots \ldots$ & $4,25 \mathrm{~mm}$ & $3,75 \mathrm{~mm}$ \\
\hline 19 segmento: $\ldots \ldots \ldots \ldots \ldots \ldots$ & $1 \mathrm{~mm}$ & $0,75 \mathrm{~mm}$ \\
\hline 20 segmento: $\ldots \ldots \ldots$ & $2,25 \mathrm{~mm}$ & $2 \mathrm{~mm}$ \\
\hline 39 segmento: . & $1 \mathrm{~mm}$ & $1 \mathrm{~mm}$ \\
\hline região anteocular: $\ldots \ldots \ldots \ldots$ & $2 \mathrm{~mm}$ & $1,75 \mathrm{~mm}$ \\
\hline região pós-ocular: $\ldots \ldots \ldots \ldots$ & $0,5 \mathrm{~mm}$ & $0,5 \mathrm{~mm}$ \\
\hline Pescoço: $\ldots \ldots \ldots \ldots \ldots \ldots \ldots$ & $0,5 \mathrm{~mm}$ & $0,5 \mathrm{~mm}$ \\
\hline $\begin{array}{l}\text { Tórax: } \ldots \ldots \ldots \ldots \ldots \ldots \ldots \ldots \ldots \ldots \\
\quad(\text { colarinho+ pronoto }+ \text { escutelo })\end{array}$ & $6,5 \mathrm{~mm}$ & $5 \mathrm{~mm}$ \\
\hline pronoto (maior largura): ..... & $5,5 \mathrm{~mm}$ & $4,5 \mathrm{~mm}$ \\
\hline escutelo: $\ldots \ldots \ldots \ldots \ldots \ldots \ldots$ & $2,5 \mathrm{~mm}$ & $2 \mathrm{~mm}$ \\
\hline processo do escutelo: . & $1,5 \mathrm{~mm}$ & $1 \mathrm{~mm}$ \\
\hline hemi-élitro: $\ldots \ldots \ldots \ldots \ldots \ldots$ & $13,5 \mathrm{~mm}$ & $11 \mathrm{~mm}$ \\
\hline Abdome: $\ldots \ldots \ldots \ldots \ldots \ldots \ldots$ & $12 \mathrm{~mm}$ & $10 \mathrm{~mm}$ \\
\hline maior largura: ...... & $7 \mathrm{~mm}$ & $6,25 \mathrm{~mm}$ \\
\hline
\end{tabular}

\section{AGRADECIMENTOS}

A Pesquisadora em Zoologia, Neide Guitton, pela assistência técnica; ao Pesquisador em Zoologia, João Barreto Gusmão, pela cessão dos espécimes de Triatoma maculata (Erichson, 1848), capturados em Surumu, Território de Roraima e ao Técnico de Laboratório, Hermenegildo N. da Cruz, pelas estereofotos e microfotografias.

\section{SUMMARY}

The recognition of the species Triatoma maculata (Erichson, 1848) and Triatoma pseudomaculata (Correia e Espinola, 1964) has been and continues to be a subject of much disagreement. These species were also confused for some time by the author.

Possibly, the reason for this confusion lies in the poor description of certain structures of these species, that one could not be certain about their distribution in Brazil.

A careful comparative study involving both species is herein reported and it is concluded that it is $\mathrm{T}$. pseudomaculata and not $\mathrm{T}$. maculata that is being found in the States of Piaui, Ceará, Rio Grande do Norte, Paraiba, Pernambuco, Alagoas, Bahia, Minas Gerais, Goiás and in the Federal District - Brasilia. 


\section{REFERENCIAS BIBLIOGRAFICAS}

1. ALENCAR, J. E. - Estudos sobre a epidemiologia da doença de Chagas no Ceará. Rev. Brasil. Malariol. D. Trop., 17: 149-158, 1965.

2. ALMEIDA, F. B. - Triatomíneos da Amazônia - Encontro de três espécies naturalmente infectados por Trypanosoma semelhante ao cruzi, no Estado do Amazonas (Hemiptera, Reduviidae). Fasc. V - Patologia Tropical| Acta Amazônica, 1: 89-93, s/ data.

3. BARRETTO, M. P. - Estudos sobre reservatórios e vetores silvestres do Trypanosoma cruzi. XVII. Rev. Soc. Bras. Med. Trop. 1: 23-36, 1967.

4. BARRETTO, M. P. - Estudos sobre reservatórios $\mathrm{e}$ vetores silvestres do Trypanosoma cruzi, XIX. Rev. Inst. Med. Trop. São Paulo, 9: 313-320, 1967.

5. CORREIA, R. R. \& ESPINOLA, H. N. - Descrição de Triatoma pseudomaculata, nova espécie de Triatomíneo de Sobral, Ceará. Arq. Hig. Saúde publ., 29: 115-127, 1964.

6. DOBBIN, J. E. Jr. \& CRUZ, A. E. Alguns informes sobre triatomíneos de Pernambuco. Rev. Bras. Malariol. D. Trop, 18: 261-267, 1966.

7. GALVÃO, A. B. \& CARVALHO, A. L. M. - Triatoma maculata (Erichson, 1848), uma espécie ocorrente em Goiás (Triatominae, Reduviidae). Rev. Bras. Malariol. D. Trop., 21, 1969.

8. LAPORTE, L. F. De - Essal d'une classification systematique de l'ordre des hemipteres. In Magasin de Zoologie publié par F. E. Guerin Deuxiéme année. 1833.
9. LUCENA, D. T. - Estudos sobre a doenca de Chagas no Nordeste do Brasil. Rev. Bras. Malariol. D. Trop. 22: $3-173,1970$.

10. NEIVA, A. — "Revisão do gênero Triatoma". 80 pp. 1914. Rio de Janeiro: Rodrigues $\mathrm{e}^{*}$ Comp.

11. NEIVA, A. \& LENT, H. - Notas e comentários sobre triatomídeos. Lista de espécies e sua distribuição geográfica. Rev. Ent., vol. 6, fasc. 2, julho, 1936 .

12. SHERLOCK, I. A. \& GUITTON, N.Sobre o Triatoma Petrochii Pinto e Barretto, 1925. Rev. Bras. Malariol. D. Trop., 19: 625-630, 1967.

13. SHERLOCK, I. A. \& SERAFIM, E. M. - Fauna Triatominae do Estado da Bahia. I - As espécies e Distribuição Geográfica. Rev. Soc. Bras. Med. Trop., 6: 265-288, 1972 .

14. STOLL, G. - Representation exactement colorée d'après nature de cigales et des punaises que se trouvent dans les quatres parties du monde, l'Europe, l'Asie, l'Afrique et l'Amerique Amsterdam, Jan Christian Sepp ed., $124+172$ pp. 29 + 141 Figs., 1788 .

15. TORREALBA, J. F. \& VASQUEZ, A. D. - Una pequeña contribución al Estudio de Focos Extradomesticos de Triatomideos Tramissores de la Enfermidad de Chagas en Venezuela. Gc. Med. Julio-Sepbre. 1953.

16. TRAVASSOS FILHO. L. P. - Carta de São Paulo, 6 de abril de 1973.

17. WALKER, F. - Catalogue of the specimens of Hemiptera Heteroptera in collection of the British Museum. London, 1873. 


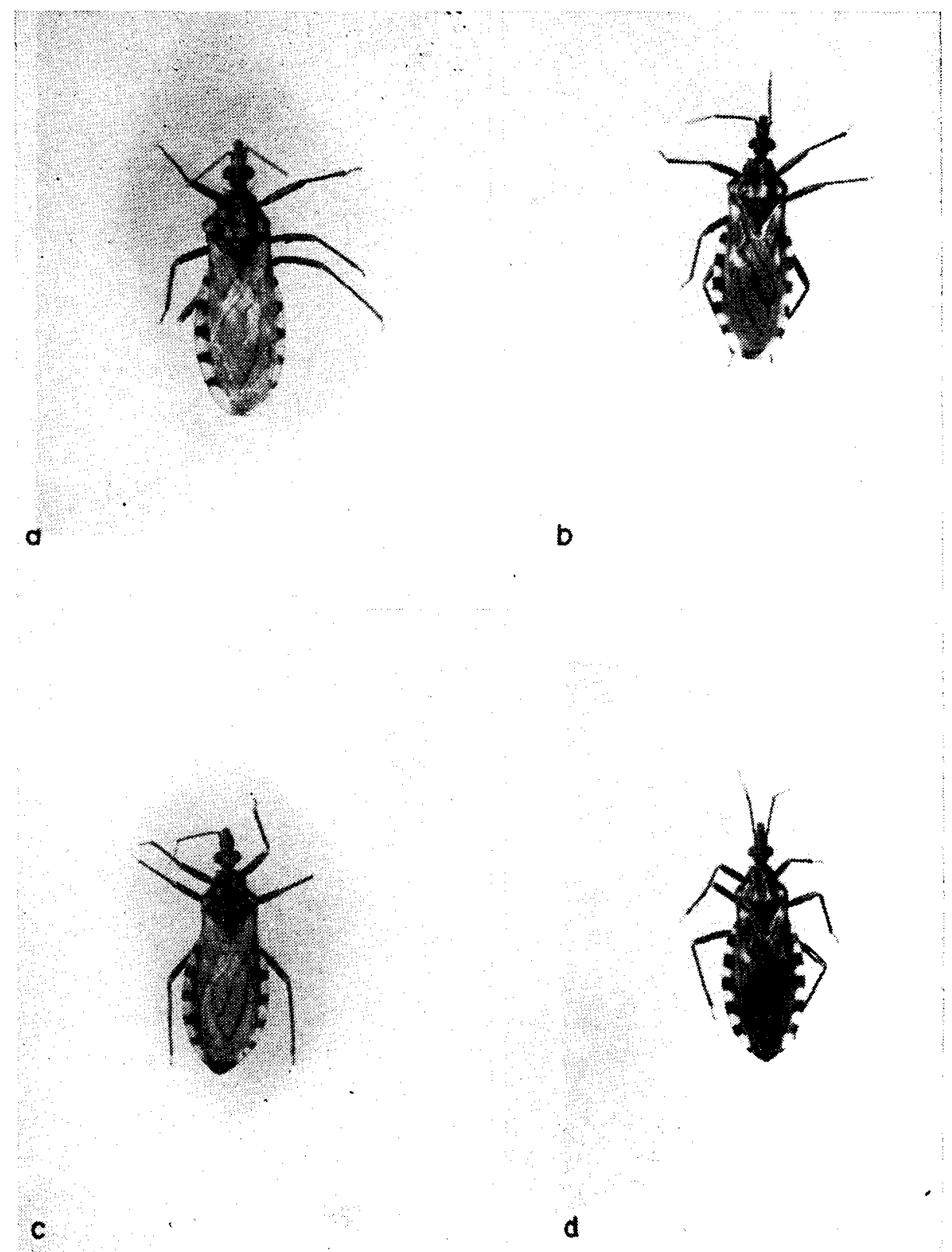

Fig. 1 - macho: a, T. maculata; b, T. pseudomaculata;

fêmea: c, T. maculata; d, T. pseudomaculata. (x20) 


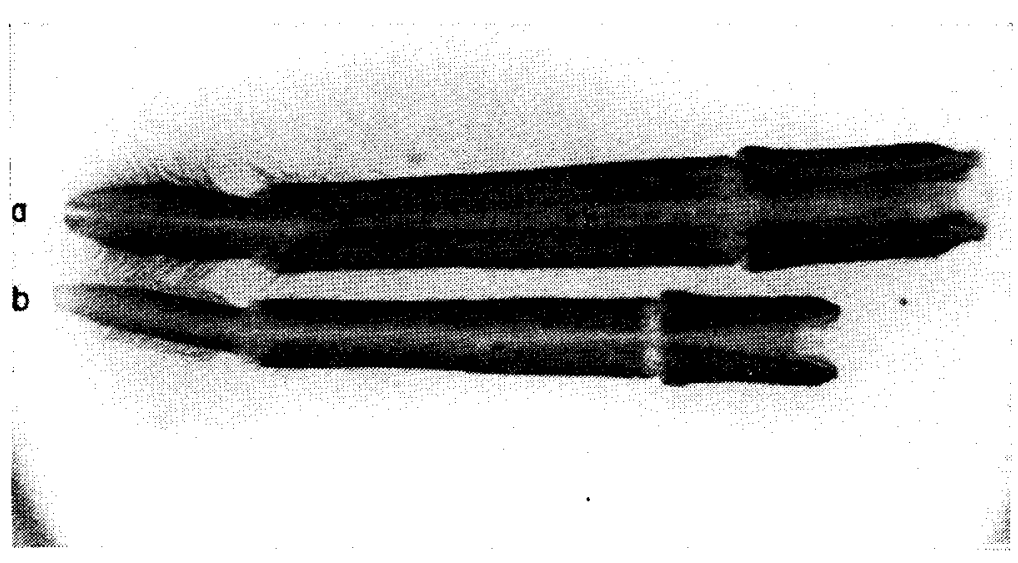

Fig. 2 - rcstro: a, T. maculata; b, T. pseudomaculata. (x20)

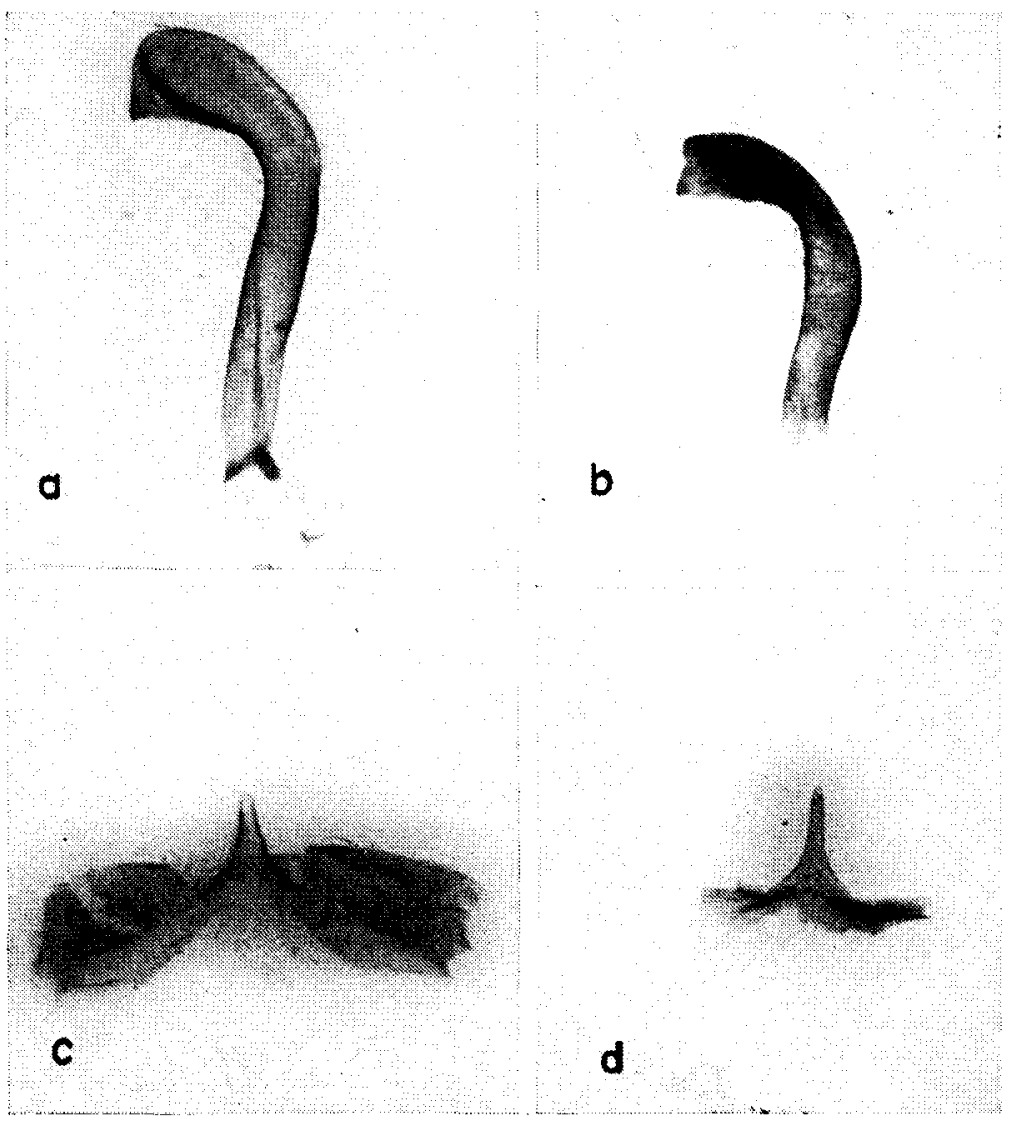

Fig. 3 - parâmeros: a, T. maculata; b. T. pseudomaculata; processo mediano do p1góforo: c, T. maculata; d, T. pseudomaculata. (x20) 

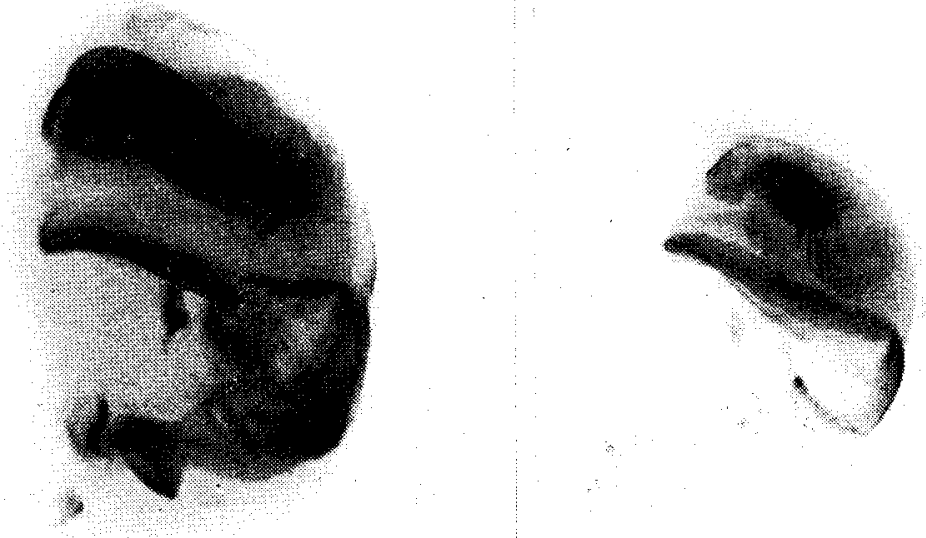

$a$

b
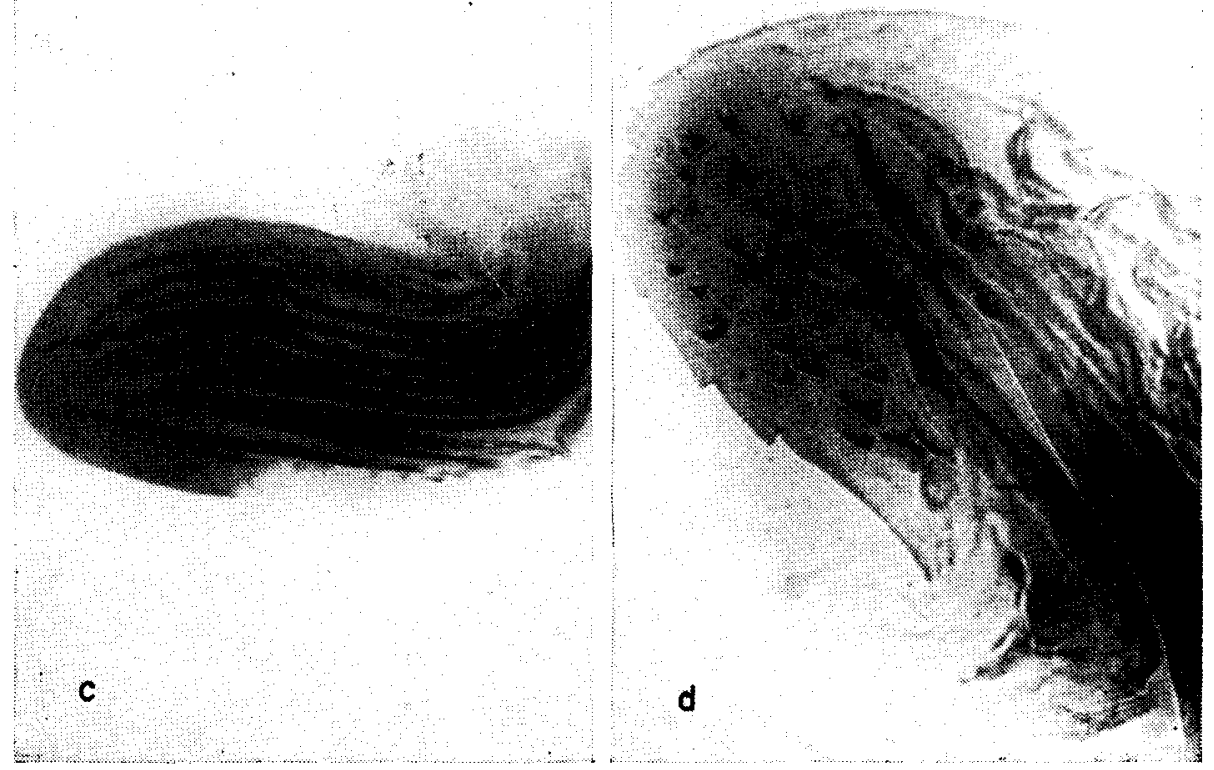

Fig. 4 - "phallus": a, T. maculata; b, T. pseudomaculata; processo do endosoma: c, T. maculata; d, T. pseudomaculata. (x50) (as demais, (x20). 


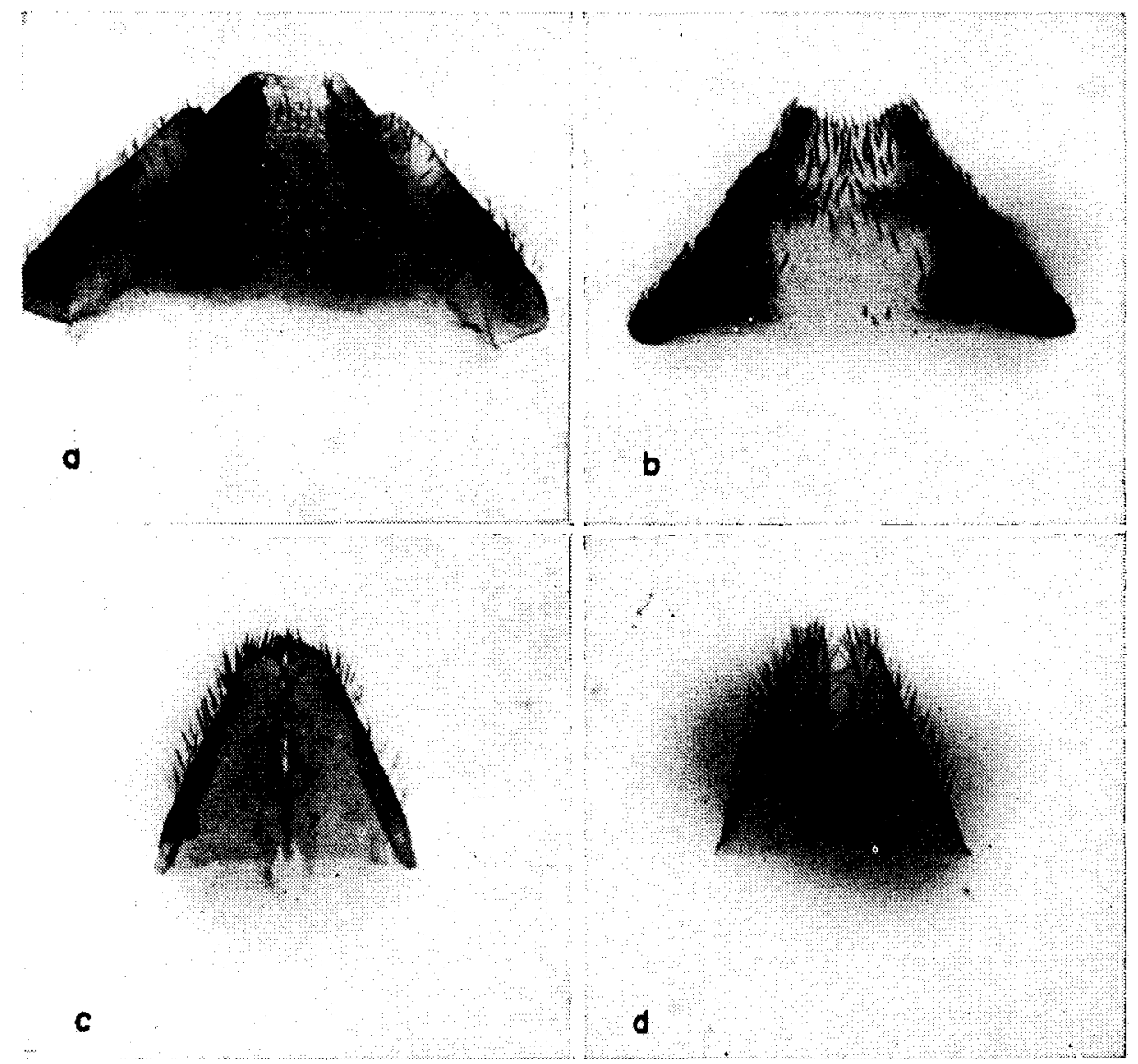

Fig. 5 - 90 e $10 \circ$ tergitos da fêmea: a, T. maculata; b, T. pseudomaculata, gonocoxitos do 90 segmento: c, T. maculata; d, T. pseudomaculata. (x20). 


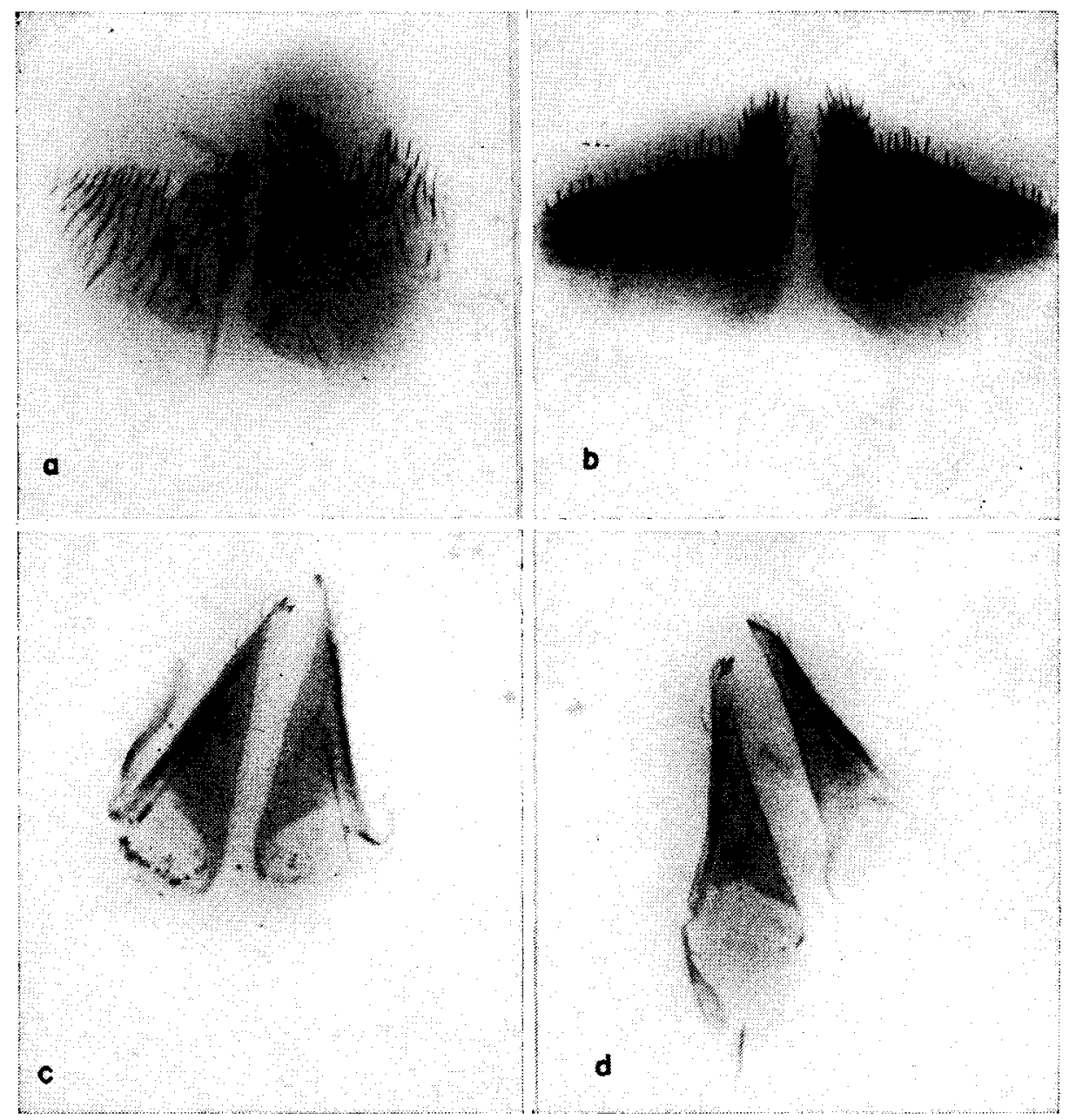

Fig. 6 - gonocoxitos e gonapófises do 80 segmento: a, T. maculata; b, T. pseudomaculata; gonapófises do 99 segmento: c, T. maculata; d, T. pseudomaculata. (x20). 
Distribuição Regional e Político do Triatoma moculata (Erichson, 1848 ) Triatomo pseudomoculato Correia e Spinolo, 1964

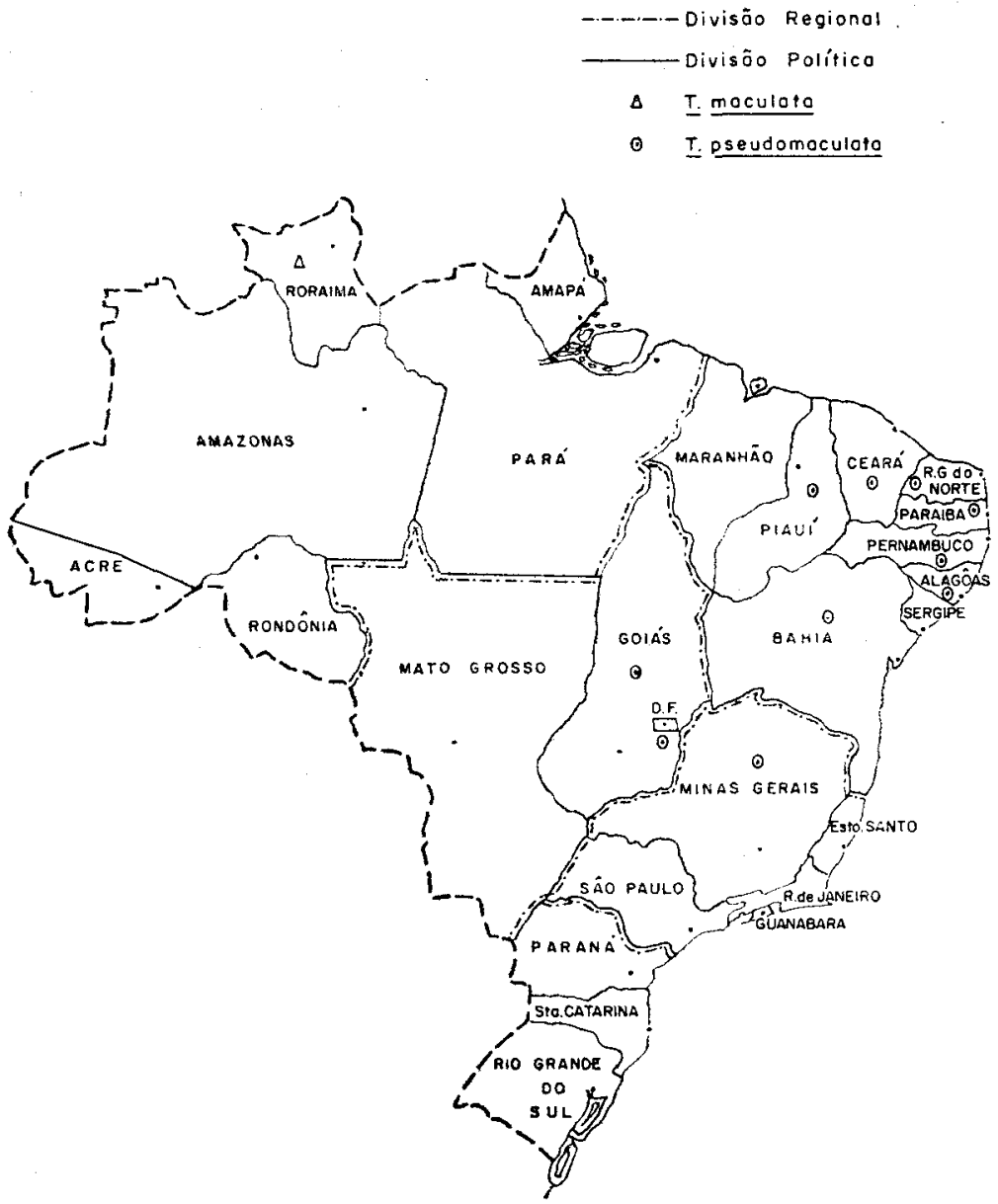

Fłg. 7 - Mapa da distribulçăo regional e polftica de ambas as espécies. 